\title{
The Effects of McKenzie Exercise on Forward Head Posture and Respiratory Function
}

\author{
SeYoon Kim¹, JuHyeon Jung ${ }^{2}$, NanSoo $\mathrm{Kim}^{3}$ \\ 'Department of Physical Therapy, Graduate School, Catholic University of Pusan, Busan; ²Department of Physical Therapy, Gimhae College, Gimhae; \\ ${ }^{3}$ Department of Physical Therapy, College of Health Science, Catholic University of Pusan, Busan, Korea
}

Purpose: This study sought to investigate the effects of the McKenzie exercise program on forward head posture and respiratory function. Methods: Thirty adult men and women with forward head posture, aged 20-29 years, were randomly assigned to the experimental group ( $N=15)$ or the control group ( $N=15)$. Subjects in the experimental group performed the McKenzie exercises three times a week for four weeks, while subjects in the control group did not receive any intervention. Craniovertebral angle (CVA) was measured to quantify forward head posture, and forced vital capacity (FVC), FVC \% predicted, forced expiratory volume at one second (FEV $)_{1}$, and FEV ${ }_{1} \%$ predicted were measured to determine changes in respiratory function. The Mann-Whitney U-test was used to analyze pre-test differences in forward head posture and respiratory function between the two groups, and the Wilcoxon signed-rank test was used to analyze differences in forward head posture and respiratory function within the groups before and after intervention. The significance level $(\alpha)$ was set to 0.05 .

Results: A comparison of pre- and post-test measures showed that CVA significantly increased in the experimental group $(p=0.001)$ denoting postural improvement, whereas no significant difference was found in the control group $(p=0.053)$. All respiratory measures, i.e.,FVC, $\mathrm{FVC} \%$ pred, $\mathrm{FEV}_{1}$, and $\mathrm{FEV}_{1} \%$ pred, were significantly improved in the experimental group, whereas there were no significant differences in the control group.

Conclusions: McKenzie exercise can be effective in improving forward head posture and respiratory function.

Keywords: Exercise therapy, McKenzie exercise, Posture, Respiration, Respiratory function test

\section{INTRODUCTION}

Forward head posture is typical in individuals who use computers in a fixed position for a prolonged period. ${ }^{1}$ During forward head posture, the head is positioned anterior to the body's center of gravity where lordosis is increased in the upper cervical region and decreased in the lower cervical region. This leads to a reduction in the overall curvature of the cervical spine and puts stress on the entire posterior spinal muscular system, especially the cervical region. ${ }^{2}$ Thus, forward head posture has long been recognized as a factor in the development of neck pain and disability. ${ }^{3-6}$

Respiration is a complex function in which the musculoskeletal and nervous systems act together. Forward head posture can give

Received Nov 4, 2019 Revised Dec 1, 2019

Accepted Dec 2, 2019

Corresponding author $\mathrm{Na}-\mathrm{Soo} \mathrm{Kim}$

E-mail hnskim@cup.ac.kr rise to abnormal changes in the anatomical structure of the cervical and thoracic sections of the spine leading to changes in respiratory function. ${ }^{7}$ In addition, changes in mobility of the cervical region, improper head posture, and dysfunction of global and local muscle systems result in muscle imbalance and instability of individual spinal segments. ${ }^{8-10}$

Abnormal head posture affects thoracic expansion, alveolar ventilation, and decreases lung volume and capacity, resulting in respiratory muscle weakness. ${ }^{11}$ Forward head posture impairs the mobility and function of the diaphragm and causes inefficient contraction of abdominal muscles, decreasing lung capacity. ${ }^{12}$ Moreover, forward head posture leads to thoracic elevation as muscle tone of the sternocleidomastoid is increased. Subsequently the mobility of

Copylight $(02019$ The Korean Society of Physical Therapy

This is an Open Access article distribute under the terms of the Creative Commons Attribution Non-commercial License (Http:// creativecommons.org/license/by-nc/4.o.) which permits unrestricted non-commercial use, distribution, and reproduction in any medium, provided the original work is properly cited. 
thoracolumbar region decreases, leading to decreased ventilator function of the diaphragm. ${ }^{13-15}$ Inefficient function of the respiratory muscle decreases its strength and thoracic expansion, hence, the ventilator function of the lungs needed during physical activity becomes impaired. ${ }^{15}$ A study by Silveira et al. ${ }^{16}$ reported that respiratory function may change because of abnormal posture. Perri and Halford ${ }^{17}$ noted that forward head posture is a compensatory posture adopted by patients with reduced respiratory function to increase their ventilator function and respiratory function. Furthermore, people with forward head posture display a tendency toward decreased respiratory function compared to those without. ${ }^{18}$

The McKenzie exercise is a self-therapeutic, repetitive exercise, focused on extension. The most frequent cause of neck pain is abnormal posture resulting in excessive stress on soft tissue and ligaments of the cervical region. This leads to changes in the structure and soft tissue of the cervical spine, thus reducing its function and causing pain. The therapeutic strategy of the McKenzie exercise includes self-therapeutic exercise, mobilization, manipulation, and patient education. This program is expected to be effective for correcting neck posture, and increasing return-to-work rate. ${ }^{19}$ In addition, it can improve function of patients, reduce recurrence of pain, and associated stress. ${ }^{20}$ The McKenzie exercise is an effective intervention for solving musculoskeletal problems and is widely used in clinical practice. Youn and Sung ${ }^{21}$ noted that head and shoulder posture significantly improved after performing the McKenzie exercise in patients with chronic neck pain. Moreover, patients with neck pain who undertook McKenzie exercise also experienced decreased pain, improved function, and positional change. ${ }^{22}$

Although there have been studies investigating the relationship between abnormal head posture and pain, studies on the relationship between forward head posture and respiratory function are inadequate. Moreover, while the McKenzie exercise has been demonstrated to be effective in decreasing pain and improving posture, there are insufficient studies on the effects of this exercise program on respiratory function. Based on past results that demonstrated the negative impact of musculoskeletal issues on respiratory function, the authors deem the McKenzie exercise to be an appropriate intervention. Therefore, the purpose of the present study was to investigate the effects of McKenzie exercise on forward head posture and respiratory function.

\section{METHODS}

\section{Subjects}

The subjects of the present study were thirty adult men and women with forward head posture who were aged 20-29 years. The subjects who understood the purpose of the study and voluntarily consented to participate were randomly assigned to one of two groups (experimental group, 15 control group, 15). Subjects with a history of surgery of the spine or thorax, traumatic neck injury, acute or chronic neuromuscular pain not related to other parts of the body, severe obesity (BMI > 40), clinical deformity of the thoracic cage or spine, serious comorbidities, diabetes, malignant tumor, or smoking were excluded. Subjects with CVA of more than $49^{\circ}$ were also excluded. The general characteristics of the subjects are shown in Table 1.

\section{Study design}

In order to determine the effects of the McKenzie exercise on for-

Table 1. General characteristics of study subjects $(N=30)$

(Mean \pm SD)

\begin{tabular}{|c|c|c|c|c|}
\hline & Experimental group & Control group & $Z^{a}$ & $\mathrm{p}$ \\
\hline Age (yr) & $22.60 \pm 2.95$ & $21.20 \pm 1.37$ & 1.67 & 0.111 \\
\hline Height $(\mathrm{cm})$ & $169.13 \pm 9.56$ & $169.52 \pm 8.27$ & -0.12 & 0.907 \\
\hline Body weight (kg) & $65.60 \pm 14.13$ & $62.53 \pm 8.53$ & 0.72 & 0.478 \\
\hline $\mathrm{BMI}\left(\mathrm{kg} / \mathrm{m}^{2}\right)$ & $22.81 \pm 3.88$ & $21.72 \pm 2.21$ & 0.95 & 0.352 \\
\hline $\operatorname{CVA}\left({ }^{\circ}\right)$ & $46.00 \pm 2.73$ & $46.27 \pm 2.26$ & -0.02 & 0.983 \\
\hline $\mathrm{FVC}(\mathrm{L})$ & $3.74 \pm 0.89$ & $3.80 \pm 0.79$ & -0.19 & 0.852 \\
\hline FVC \%pred & $86.60 \pm 10.05$ & $86.33 \pm 7.13$ & -0.06 & 0.950 \\
\hline $\mathrm{FEV}_{1}(\mathrm{~L})$ & $3.43 \pm 0.83$ & $3.59 \pm 0.75$ & -0.54 & 0.589 \\
\hline $\mathrm{FEV}_{1} \%$ pred & $91.80 \pm 11.43$ & $95.40 \pm 7.00$ & -1.23 & 0.219 \\
\hline
\end{tabular}

BMI: body mass index, CVA: craniovertebral angle, FVC: forced vital capacity, FEV 1 : forced expiratory volume at one second, SD: standard deviation. aMann-Whitney U-test. 
ward head posture and respiratory function, the randomized trial selected subjects whose craniovertebral angle (CVA) was less than $49^{\circ}$ as a reference. ${ }^{23}$ The subjects in the experimental group underwent McKenzie exercise, whereas the control group received no intervention. This was done to measure changes in CVA and respiratory function from pre-intervention to post-intervention (after four weeks of exercise) in the experimental group. Furthermore, changes in CVA and respiratory function from pre-intervention to post-intervention between the two groups were analyzed. This study was approved by the Bioethics Committee of the Catholic University of Pusan (CUPIRB-2013-015).

\section{1) Intervention}

Subjects in the experimental group performed the McKenzie exercise as an intervention to treat forward head posture. The exercise routine consisted of seven types of movements, at static maximal strength, with 15 to 20 repetitions, holding each repetition for seven seconds. The subjects completed one 20-minute set per day, three times a week for four weeks. To ensure the subjects performed the exercise accurately, sufficient explanation and demonstrations were provided and exercise on day one was monitored by the investigator. An exercise manual and log were provided to measure performance to ensure program compliance, and were periodically checked by the investigator. The exercises were performed in the following order: head retraction with overpressure while sitting, neck extension while sitting, head retraction with overpressure while lying, neck extension while lying, side bending of the neck while sitting, neck rotation while sitting, and neck flexion with chin-in in the sitting position. ${ }^{19}$

For head retraction with overpressure while sitting, the subjects slowly pulled their head toward the back as much as possible, with the chin tucked, and held this position for seven seconds before returning to the initial position. Here, the gaze was focused in the front, and the head was not tilted back. The chin was pushed back with both hands to apply pressure. For neck extension while sitting, the subjects tilted their head backwards as if looking at the sky and held the position for seven seconds before returning to the initial position. The subjects were instructed not to push their neck forward.

For head retraction with overpressure while lying, the subjects slowly pulled their head toward the back as much as possible in a ly- ing position, with chin tucked, and held this position for seven seconds before returning to the initial position. Here, the gaze was focused upwards, and the head was not tilted back. The chin was pushed back with both hands to apply pressure. For neck extension while lying, the subjects were lying down with the head positioned outside the bed and raised their chin by tilting the head backwards as if looking at the sky and holding the position for seven seconds before returning to the initial position. Here, the subjects were instructed not to push their neck forward.

For turning of the neck while sitting, the subjects sat on a chair and bent their head sideways to bring their right ear close to the right shoulder, while keeping the head pulled back, and held the position for seven seconds. This was repeated on the left side. Here, the subjects were instructed to keep their head stationary and use their hands to help turn their head. For neck rotation while sitting, the subjects sat in a chair and turned their neck as much as possible, while keeping the head pulled back, and held the position for seven seconds before returning to the initial position. This was repeated on the opposite side. Both hands were used to help turn the head. For neck flexion with chin-in while sitting, the subjects tilted their head toward their chest and held the position for seven seconds, while keeping the head pulled back, before returning to the initial position. The head was pushed down with both hands with fingers interlocked in such a way that the elbows pointed downwards.

\section{Experimental methods}

\section{1) Measurement tools}

\section{(1) Craniovertebral angle}

CVA and respiratory function were measured. CVA is a method used for measuring forward head posture and represents the position of the head with respect to $\mathrm{C} 7$ when observed from the lateralview. The CVA is the angle between the horizontal line passing through the $\mathrm{C} 7$ spinous process and a line extending from the midpoint of the tragus of the ear to the $\mathrm{C} 7$ spinous process. Smaller CVA indicates greater forward head posture. ${ }^{24}$ The subjects placed their arms by their side and were instructed to maintain an upright posture and direct their gaze to a marked point at eye level. In order to ensure accuracy when taking pictures, the position of the tragus and spinous processes of the $\mathrm{C} 7$ were marked. A digital camera (IXUS951S, Canon, Tokyo) was used to take pictures, and Image J (Rasband, USA) was used for CVA measurement. ${ }^{25}$ In the present 
study, forward head posture was defined as CVA of less than $49^{\circ} .{ }^{23}$ CVA measurement is shown in Figure 1.

\section{(2) Respiratory function}

The respiratory function of each subject was measured using a spirometer (SP-260 Pneumotach Sensor, SCHILLER, Switzerland). For accurate measurement, sufficient explanation and demonstration were provided before testing three times. The most consistent results were selected as data. The tests were performed in a standing position and the parameters measured were forced vital capacity (FVC), forced vital capacity \%predicted (FVC \%pred), forced expiratory volume at one second $\left(\mathrm{FEV}_{1}\right)$, and forced expiratory volume at one second \%predicted ( $\mathrm{FEV}_{1}$ \%pred). FVC is the amount of air exhaled after inhaling as much air as possible and can be used to assess the presence of restrictive pulmonary disease. $\mathrm{FEV}_{1}$ is the volume of gas exhaled during the first second of the FVC measurement and can be used to determine the presence of obstructive pulmonary disease. ${ }^{26}$ In addition, the present study determined the \%pred

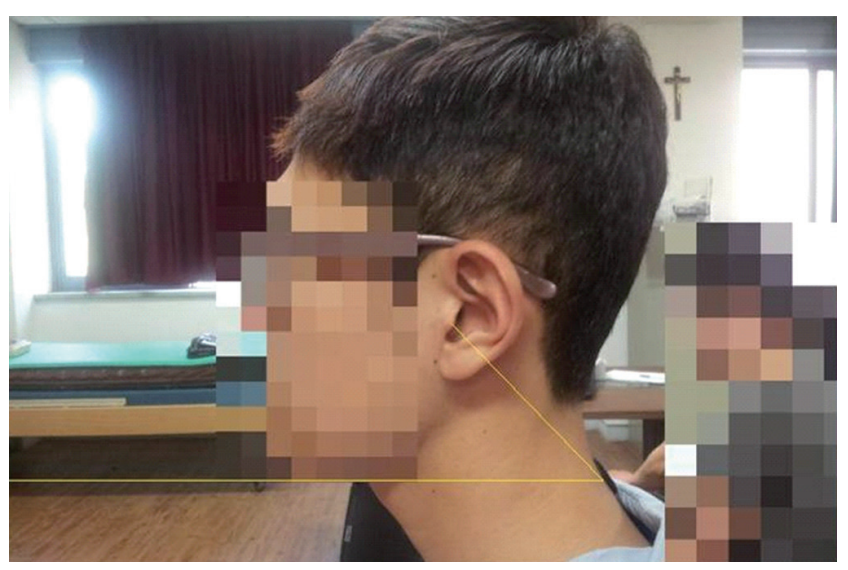

Figure 1. Measurement of craniovertebral angle. values, a normal value expected for someone of the same sex, age, height, and weight as the subjects. ${ }^{27}$

\section{Statistical analysis}

The present study calculated the percentages and means of the general characteristics of the subjects. Statistical analysis was performed using the non-parametric method because the normality test was not satisfied. The before and after intervention differences in forward head posture and respiratory function between the two groups were analyzed using the Mann-Whiney $U$ test, and withingroup differences before and after intervention were analyzed using the Wilcoxon signed-ranks test. The data were analyzed using PASW version 18.0 (SPSS Inc, USA). The significance level ( $\alpha$ ) was set to 0.05 .

\section{RESULTS}

The pre-and post-intervention measures of CVA for the experimental and control groups are shown in Table 2. CVA significantly increased after four weeks of intervention in the experimental group $(\mathrm{p}<0.05)$. There was no significant difference in CVA after four weeks in the control group ( $\mathrm{p}>0.05)$.

The difference in respiratory function between the experimental and control groups is shown in Table 2. FVC and FVC \%pred in the experimental group show significant increases after four weeks of intervention $(\mathrm{p}<0.05)$. Whereas no significant differences are noted in either parameter in the control group $(p>0.05)$. Similarly, FEV and $\mathrm{FEV}_{1}$ \%pred were significantly increased after four weeks of intervention $(\mathrm{p}<0.05)$. Conversely, the control group showed no significant difference in either outcome ( $p>0.05)$ (Table 2).

Table 2. Comparisons of craniovertebral angle and respiratory function between exercise and control groups $(\mathrm{N}=30)$

$($ Mean \pm SD)

\begin{tabular}{|c|c|c|c|c|c|}
\hline & Group & Pre-test & Post-test & $\mathrm{Z}^{\mathrm{a}}$ & $p$ \\
\hline \multirow[t]{2}{*}{$\operatorname{CVA}\left({ }^{\circ}\right)$} & Exercise & $46.00 \pm 2.73$ & $51.14 \pm 3.67$ & -3.41 & 0.001 \\
\hline & Control & $46.27 \pm 2.26$ & $48.39 \pm 2.80$ & -1.94 & 0.053 \\
\hline \multirow[t]{2}{*}{ FVC (L) } & Exercise & $3.74 \pm 0.89$ & $4.01 \pm 0.87$ & -3.41 & 0.001 \\
\hline & Control & $3.80 \pm 0.79$ & $3.75 \pm 0.79$ & -0.91 & 0.363 \\
\hline \multirow[t]{2}{*}{ FVC \%pred } & Exercise & $86.60 \pm 10.05$ & $93.00 \pm 10.17$ & -3.43 & 0.001 \\
\hline & Control & $86.33 \pm 7.13$ & $85.00 \pm 7.09$ & -1.43 & 0.153 \\
\hline \multirow[t]{2}{*}{$\mathrm{FEV}_{1}(\mathrm{~L})$} & Exercise & $3.43 \pm 0.83$ & $3.71 \pm 0.89$ & -2.96 & 0.003 \\
\hline & Control & $3.59 \pm 0.75$ & $3.67 \pm 0.80$ & -1.42 & 0.155 \\
\hline \multirow[t]{2}{*}{ FEV 1 \%pred } & Exercise & $91.80 \pm 11.43$ & $99.93 \pm 12.80$ & -2.99 & 0.003 \\
\hline & Control & $95.40 \pm 7.00$ & $96.40 \pm 8.48$ & -0.91 & 0.362 \\
\hline
\end{tabular}

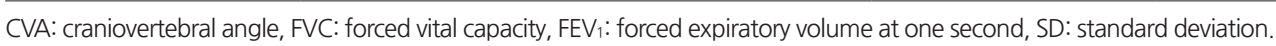

ailcoxon Signed rank test. 
Table 3. Comparisons of craniovertebral angle and respiratory function between exercise and control groups after four weeks intervention $(\mathrm{N}=30)$

\begin{tabular}{lcccc}
\hline & Exercise & Control & Z $^{\text {a }}$ & p \\
\hline CVA $\left(^{\circ}\right)$ & $51.14 \pm 3.67$ & $48.39 \pm 2.80$ & -1.99 & 0.046 \\
FVC (L) & $4.01 \pm 0.87$ & $3.75 \pm 0.79$ & -0.723 & 0.467 \\
FVC \% pred & $93.00 \pm 10.17$ & $85.00 \pm 7.09$ & -2.02 & 0.043 \\
FEV ${ }_{1}(\mathrm{~L})$ & $3.71 \pm 0.89$ & $3.67 \pm 0.80$ & -0.27 & 0.787 \\
FEV ${ }_{1} \%$ pred & $99.93 \pm 12.80$ & $96.40 \pm 8.48$ & -0.93 & 0.350 \\
\hline
\end{tabular}

CVA: craniovertebral angle; FVC: forced vital capacity; FEV : forced expiratory volume at one second; SD, standard deviation. aMann-Whitney U-test.

The post-intervention measures of CVA and respiratory function between the experimental and control groups are shown in Table 3. After four weeks, CVA and FVC \%pred in the experimental group show significant increases $(\mathrm{p}<0.05)$. There was no significant difference in $\mathrm{FVC}, \mathrm{FEV}_{1}$ and $\mathrm{FEV}_{1}$ \%pred after four weeks ( $\mathrm{p}>0.05$ ).

\section{DISCUSSION}

This study sought to determine the effects of the McKenzie exercise on forward head posture and respiratory function. This was based on previous work which showed that respiratory function of people with forward head posture is weaker than that of those with normal head posture. ${ }^{18}$

Forward head posture also increases thoracic kyphosis which affects thoracic movement, and has a negative impact on respiratory function. ${ }^{25}$ The higher degrees of rounded shoulder posture correlate with lower respiratory function. ${ }^{28}$ Although no significant ventilation problems occur even with severe deformation of the thoracic spine, it results in short and shallow respiration, an increased respiration rate and decreased lung flexibility. ${ }^{29} \mathrm{Kim}$ et al. ${ }^{18}$ assigned those with forward head posture to the experimental group in order to compare their post-intervention respiratory function with healthy controls. The results showed that FVC \%pred of the experimental group was $81.95 \%$ and that of the control group was $93.54 \%$. In addition, they reported that $\mathrm{FEV}_{1}$ \%pred of the experimental group was $90.20 \%$, which was significantly lower than that of the control group (99.62\%). Previous study reported that lung capacity decreased by $19.9 \%$ in healthy individuals with forward head posture compared to a neutral, standing position. ${ }^{30}$ Similarly, Almeida et al. ${ }^{31}$ evaluated the relationship between respiratory function and posture in 34 asthmatic adults. The results demonstrated that postural change affects respiratory function.
Various interventions to improve forward head posture have been investigated. A study found that applying joint mobilization techniques on patients with neck dysfunction significantly increased the neck's range of motion. ${ }^{32}$ In addition, Kim et al. ${ }^{33}$ divided 30 subjects with forward head posture into sustained natural apophyseal glide and control groups to compare the postural change of the neck and reported that there was significant postural improvement of the neck in the experimental group.

In the present study, the CVA of the experimental group significantly increased from $46.00^{\circ}$ pre-exercise to $51.14^{\circ}$ post-exercise. These results are similar to ones who examined CVA changes in groups undergoing McKenzie exercise with conventional therapy versus only conventional therapy. ${ }^{21}$ Their results showed that the CVA of subjects in combined therapy significantly improved in just one to two weeks compared to four weeks for the conventional therapy group. Moreover, Jung 22 compared pre- and post-intervention pain and CVA after McKenzie exercise in 15 subjects with chronic neck pain. They reported improvements in pain and CVA after the intervention. Therefore, the results of the present study are in agreement with the literature which demonstrates that McKenzie exercise corrects abnormal posture and can shorten the time toward postural improvement.

Specific hold and relax stretching technique is significantly correlated with increased FVC and chest expansion. ${ }^{34}$ Moreover, Hwangbo et al. ${ }^{35}$ divided 45 chronic neck pain patients with thoracic kyphosis into various intervention groups i.e.only thoracic mobilization, only self-stretching exercise, and both, in order to measure preand post-test range of motion and respiratory function. The results showed that both parameters significantly improved in all three groups. In the present study, subjects were divided evenly into intervention i.e. McKenzie exercise and non-intervention groups. Respiratory function was measured pre- and post-intervention and the 
results show that FVC, FVC \%pred, $\mathrm{FEV}_{1}$, and $\mathrm{FEV}_{1}$ \%pred significantly increased in the intervention cohort. This result, along with the supporting literature, indicates that improved posture from exercise may also improve respiratory function.

A review of previous studies on forward head posture and respiratory function concluded that cervical lordosis and range of motion are decreased in people with forward head posture. Moreover, it was demonstrated that thoracic kyphosis is increased and thoracic movement is affected, possibly reducing respiratory function. To address the need for an intervention, the present study showed that McKenzie exercise is effective in improving forward head posture and restoring respiratory function. The study applied effective interventions to reduce respiratory function, CVA. This method improves incomplete posture or imbalance of muscle strength in subjects with frontal posture by adapting the motion along three directions of movement. in addtion, this intervention also improved the abnormal stress of the tissue due to muscle length. ${ }^{36,37}$ Thus we believe that the McKenzie exercise program will contribute toward posture recovery and improving decreased respiratory function in individuals with forward head posture. There were some limitations to the current study. The subjects herein were young adults, which hinders the broader applicability of the current findings. Moreover, we were not able to determine how long the effect of intervention is sustained after the completion of the program. Thus, future studies could explore the long-term effects of McKenzie exercise in various age groups.

The present study aimed to determine the effects of the McKenzie exercise program on forward head posture and respiratory function. In the group undergoing McKenzie exercise, forward head posture, FVC, FVC \%pred, FEV , and FEV $_{1}$ \%pred were significantly improved after intervention. Despite a small sample size and lack of long-term follow up, it is suggested that McKenzie exercise will be effective in improving forward head posture and respiratory function.

\section{REFERENCES}

1. Kang JH, Park RY, Lee SJ et al. The effect of the forward head posture on postural balance in long time computer based worker. Ann Rehabil Med. 2012;36(1):98-104.

2. Morningstar M. Cervical curve restoration and forward head posture reduction for the treatment of mechanical thoracic pain using the pettibon corrective and rehabilitative procedures. J Chiropr Med. 2002;1(3):113-
5.

3. Chae YW. The measurement of forward head posture and pressure pain threshold in neck pain. J Kor Phys Ther. 2002;14(1):117-24.

4. Harrison DE, Haas JW, Cailliet R et al. Concurrent validity of flexicurve instrument measurements sagittal skin contour of the cervical spine compared with lateral cervical radiographic measurements. J Manipulative Physiol Ther. 2005;28(8):597-603.

5. Chae YW. The effect of forward head posture and cervical ROM on chronic and episodic tension-type headache in university students. J Kor Phys Ther. 2009;21(2):71-7.

6. Kim IG, Lee SY. The effect of forward head posture and tension type headache on neck movement: for office worker. J Kor Phys Ther. 2018; 30(6):218-23.

7. Kapreli E, Vourazanis E, Strimpakos N. Neck pain causes respiratory dysfunction. Med Hypothesis. 2008;70(5):1009-13.

8. Comerford MJ, Mottram SL. Movement and stability dysfunction-contemporary developments. Man Ther. 2001;6(1):15-26.

9. Key J, Clift A, Condie F, et al. A model of movement dysfunction provides a classification system guiding diagnosis and therapeutic care in spinal pain and related musculoskeletal syndromes: a paradigm shiftpart 1. J Bodyw Mov Ther. 2008;12(1):7-21.

10. Dimitriadis Z, Kapreli E, Strimpakos N et al. Respiratory weakness in patients with chronic neck pain. Man Ther. 2013;18(3):248-53.

11. Pires MG, Di Francesco RC, Grumach AS et al. Evaluation of inspiratory pressure in children with enlarged tonsils and adenoids. Braz J Otorhinolaryngol. 2005;71(5):598-602.

12. Okuro RT, Morcillo AM, Ribeiro MÂ et al. Mouth breathing and forward head posture: effects on respiratory biomechanics and exercise capacity in children. J Bras Pneumol. 2011;37(4):471-9.

13. Huggare JA, Laine-Alava MT. Nasorespiratory function and head posture. Am J Orthod Dentofacial Orthop. 1997;112(5):507-11.

14. Lima LC, Baraúna MA, Sologurem MJ et al. Postural alterations in children with mouth breathing assessed by computerized biophotogrammetry. J Appl Oral Sci. 2004;12(3):232-7.

15. Corrêa EC, Bérzin F. Mouth breathing syndrome: cervical muscles recruitment during nasal inspiration before and after respiratory and postural exercises on Swiss Ball. Int J Pediatr Otorhinolaryngol. 2008;72(9): 1335-43.

16. Silveira WD, Mello FC, Guimarães FS et al. Postural alterations and pulmonary function of mouth-breathing children. Braz J Otorhinolaryngol. 2010;76(6):683-6.

17. Perri MA, Halford E. Pain and faulty breathing: a pilot study. J Bodyw Mov Ther. 2004;8(4):297-306.

18. Kim SY, Kim NS, Jung JH et al. Effect of forward head posture on respiratory function in young adults. J Kor Phys Ther. 2013;25(5):311-5.

19. McKenzie RA. The cervical and thoracic spine. New Zealand: Spinal pubilcations; 1990.

20. Toilson CD, Michael LK. Physical exercise in the treatment of low back pain. part I A review. Orthop Rev. 1998;17(7):724-9.

21. Youn JH, Sung DJ. The influence of McKenzie Approach on head, shoulder posture of the patients with chronic neck pain. The Research Institute of Physical Education \& Sports Sci. 1998;17:79-90.

22. Jeong YW. Effects of McKenzie exercise on the functional recovery and forward head posture of chronic neck pain patients. J Kor Soc Phys Med. 
2006;1(1):93-108.

23. Nemmers TM, Miller JW, Hartman MD. Variability of the forward head posture in healthy community-dwelling older women. J Geriatr Phys Ther. 2009;32(1):10-4.

24. Raine S, Twomey LT. Head and shoulder posture variations in 160 asymptomatic women and men. Arch Phys Med Rehabil. 1997;78(11): 1215-23.

25. Quek J, Pua YH, Clark RA et al. Effects of thoracic kyphosis and forward head posture on cervical range of motion in older adults. Man Ther. 2013;18(1):65-71.

26. American Thoracic Society. Standardization of spirometry, 1994 update. Am J Respir Crit Care Med. 1995;152(3):1107-36.

27. Song JY, The changes of respiratory functions following postures in cerebral palsy. J Kor Phys Ther. 2004;16(4):115-28

28. Ghanbari A, Ghaffarinejad F, Mohammadi F et al. Effect of forward shoulder posture on pulmonary capacities of women. Br J Sports Med. 2008;42(7):622-3.

29. Lonstein JE, Breadford DS, Oglivis JW, Winter RB. Moe's textbook of scoliosis \& other spinal deformities. 3rd ed. Philadelphia. 1994.

30. Song JY, Sim HV, Current ME et al. A comparison of vital capacity values with healthy subjects in standing and head-down positions. Phys Ther Korea. 1996;3(1):40-7.
31. Almeida VP, Guimarães FS, Moço VJ et al. Correlation between pulmonary function, posture, and body composition in patients with asthma. Rev Port Pneumol. 2013;19(5):204-10.

32. Wood TG, Colloca CJ, Matthews R. A pilot randomized clinical trial on the relative effect of instrumental (MFMA) versus manual (HVLA) manipulation in the treatment of cervical spine dysfunction. J Manipulative Physiol Ther. 2001;24(4):260-71.

33. SY, Kim NS, Kim LJ. Effects of sustained natural apophyseal glide on forward head posture and respiratory function. J Phys Ther Sci. 2015; 27(6):1851-4.

34. Putt MT, Watson M, Seale H et al. Muscle stretching technique increases vital capacity and range of motion in patients with chronic obstructive pulmonary disease. Arch Phys Med Rehabil. 2008;89(6):1103-7.

35. Hwangbo PN, Hwangbo G, Park JS et al. The effect of thoracic joint mobilization and self-stretching exercise on pulmonary functions of patients with chronic neck pain. J Phys Ther Sci. 2014;26(11):1783-6.

36. Rathore S. Use of McKenzie cervical protocol in the treatment of radicular neck pain in a machine operator. J Can Chiropr Assoc. 2003;47(4): 291-7.

37. Na JG, Lee HS, Park SW. Effects of exercise type on neck disability, pain, and postural changes in subjects with forward head posture: systematic review and meta-analysis. J Kor Soc Phys Med. 2018;13(3):121-32. 